\title{
Some aspects of the process development forecast the spread of COVID 19 infection.
}

\section{Valeri Kotelnikov ( $\square$ tikopr@mail.ru )}

Tuvinian institue for exploration of natural resourses of Russian academy of sci https://orcid.org/0000-0001-7481-9770

\section{Michail Krasilnikov}

Tuvinian institue for exploration of natural resourses of Russian academy of sci

https://orcid.org/0000-0003-0747-6936

\section{Elena Ryazanova}

Tuvinian Research Institute Russian academy of sciences

\section{Rosa Chysyma}

Tuvinian Research Institute Russian academy of sciences

\section{Biological Sciences - Article}

Keywords: COVID-19, SARS-CoV-2, Gaussian distribution

Posted Date: November 20th, 2020

DOl: https://doi.org/10.21203/rs.3.rs-110358/v2

License: (c) (i) This work is licensed under a Creative Commons Attribution 4.0 International License. Read Full License 


\section{Abstract}

The world community is experiencing a pandemic of the COVID-19 virus and is looking for ways to solve the problems that have arisen due the spread of a new infection. The Tuvinian Institute for the Exploration of Natural Resources of the SB RAS does not stand aside from important work to combat the spread of the virus. We tried to analyze the available data for the Republic of Tuva, Russia and the world. In this work, we used data from the sites of stopcoronavirus.rf, worldometers.info, Yandex.com and others. For successful control of SARS-CoV-2, it is important to take preventive measures as early as possible and prepare medical institutions to combat the spread of the virus, which can be ensured by analyzing the previous development of the process and building a model for planning. The analysis is carried out using the mathematical apparatus of the normal distribution (Gauss), which, in our opinion, most closely describes the laws of the process.

\section{Introduction}

The world community is experiencing a pandemic of the COVID-19 virus and is looking for ways to solve the problems that have arisen due the spread of a new infection. The Tuvinian Institute for the Exploration of Natural Resources of the SB RAS does not stand aside from important work to combat the spread of the virus. We tried to analyze the available data for the Republic of Tuva, Russia and the world. In this work, we used data from the sites of stopcoronavirus.rf, worldometers.info, Yandex.com and others. For successful control of SARS-CoV-2, it is important to take preventive measures as early as possible and prepare medical institutions to combat the spread of the virus, which can be ensured by analyzing the previous development of the process and building a model for planning.

\section{Results}

The analysis is carried out using the mathematical apparatus of the normal distribution (Gauss), which, in our opinion, most closely describes the laws of the process:

$$
f(x)=A * e^{-0,5 *\left(\frac{x-D m}{D h}\right)^{2}}
$$

A visual demonstration of this approach is given at figure 1 .

To assess the parameters of the process, the indicator of the number of infected patients was used, since the use of, for example, active patients is incorrect, since the difference between the number of patients and the number of those who recovered is two sides of the same coin. The sick will surely recover, the difference between them is the number of sick people during the recovery period. The main parameters of the process: maximum amplitude 3409 people, maximum day 118, half width 23 days. The maximum day and half-width on the graph of the COVID 19 infection function appear to be characteristic process parameters and can be used for forecasting and planning health measures. As a result of the assessment 
of the forecast parameters as of June 15, 2020, it was established that the process of infection development in the republic can last 118 days, the peak incidence can be passed in 20-25 days (i.e. July $10-15,2020)$.The process of spreading the virus can be completely stopped in the absence of dramatic changes in the prevention of the disease, after 100-110 days (mid-October 2020). In total, 3000-3500 people can get sick. Our forecasts for the Tyva Republic have been confirmed.

Analysis of the process based on data from 188 countries of the world shows that the key characteristic of the spread of the epidemic is the time to reach the maximum of cases. On average, this is about 90 days from the first detection of the infection.

If the country takes active steps to reduce the incidence, it is possible to change the course of the process and reduce the number of active cases of the disease by $30-40 \%$. For example, in Russia, the country's leadership took large-scale measures to prevent the spread of the virus, and as a result, in the summer of 2020 , it was possible to reduce the number of infected people (Fig. 2).

The accuracy of the calculation is \pm 8 days. The accuracy is determined by the method of collecting the initial data.

In the process of analyzing statistical data, we made an attempt to determine external general factors that affect the spread of the virus. Estimates were made of the correlation between the increase in morbidity from solar insolation; the length of the day was chosen as an indicator. Figure 3 shows the comparison results.

Similarly, you can assess the impact of solar radiation on the spread of COVID 19, if you compare the development of the process in the southern and northern hemispheres. This dependence is shown in Fig. 4.

Figure 4 shows that the increase and decrease in the incidence of COVID 19 are in antiphase in different hemispheres, which indicates the seasonal nature of the development of the process.

Based on this, it can be assumed that the climatic factors of the planet affect the pandemic. It can be expected that the process peaks in the northern hemisphere will be in seasons with minimum solar radiation and average temperatures, in spring and autumn. In summer, an excess of UV radiation from the sun and the maximum concentration of active oxygen will lead to a decrease in morbidity. In winter, one should also expect a certain decline in the incidence due to a drop in air temperature below zero, which will lead to the freezing of moisture from the air, which, as you know, is a carrier of the virus. Based on the model of the process, while maintaining the conditions for the development of the process, in the absence of sharp influences on it, the amplitude of the second wave may reach values of about 40,000 infected per day and then will decline.

The process of the spatial spread of the virus was analyzed using the Monte Carlo method. Initially, the task was set to determine how the average patient who does not have obvious symptoms of the disease, who uses public transport every day to travel to and from work and back to the store, can infect others 
around him. The condition for going to a doctor and isolation is to get a positive test. As a result of calculations, it was determined that such a patient in 7 days (the average time for obtaining a positive result) can infect a maximum of 1000 people, about 140 people a day.

Based on the foregoing, it is possible to offer recommendations for planning additional measures to combat the infection. First of all, it is necessary to minimize the time to obtain test results for the presence of COVID 19 disease as much as possible, which will significantly reduce the rate of spread of the virus. To recommend to the population walks in the fresh air in combination with strict fulfillment of the requirements for observing the mask regime and social distance, to make the most of the possibilities of tanning salons. To motivate the population to move to summer cottages, country houses, to make the most of the possibilities of remote work.

\section{References}

1. Del Rio C., Malani P. N. 2019 novel coronavirus-important information for clinicians //Jama. - 2020. - T. 323. - №. 11. - C. 1039-1040.

2. Guan, W. J., et al. "China Medical Treatment Expert Group for Covid-19. 28 February 2020, posting date. Clinical characteristics of coronavirus disease 2019 in China." New England Journal of Medicine. - 2020. - C. 1708-1720.

3. Thomas, P., Baldwin, C., Bissett, B., Boden, I., Gosselink, R., Granger, C. L., Hodgson C, Jones AYM, Kho ME, Moses R, Ntoumenopoulos, G. Physiotherapy management for COVID-19 in the acute hospital setting: clinical practice recommendations. // Journal of Physiotherapy. - 2020. V. 66,№ 2, P. 73-82.

4. Nsoesie, E. O., Beckman, R. J. \& Marathe, M. V. Sensitivity analysis of an individual-based model for simulation of influenza epidemics. PLoS ONE 7, 0045414 (2012).

5. Ferguson, N. M. et al. Imperial College COVID-19 Response Team. Impact of non-pharmaceutical interventions (NPIs) to reduce COVID-19 mortality and healthcare demand. Preprint at https://doi.org/10.25561/77482 (2020).

6. Eubank, S. et al. Modelling disease outbreaks in realistic urban social networks. Nature 429, 180 (2004).

7. Moss, R. et al. Modelling the impact of COVID-19 in Australia to inform transmission reducing measures and health system preparedness. medRxiv https://doi.org/10.1101/2020.04.07.20056184 (2020).

8. Harding, N., Spinney, R. E. \& Prokopenko, M. Population mobility induced phase separation in SIS epidemic and social dynamics. Sci. Rep. 10, 7646 (2020).

9. Hoang, A. et al. COVID-19 in 7780 pediatric patients: a systematic review. EClinicalMedicine 24, 100433 (2020).

10. Group of Eight (Go8) Australian Universities Taskforce. COVID-19 Roadmap to Recovery: A Report for the Nation (Group of Eight (Go8) Australian Universities Taskforce, 2020). 
11. Small, M. \& Cavanagh, D. Modelling strong control measures for epidemic propagation with networks -a COVID-19 case study. IEEE Access 8, 109719-109731 (2020).

12. Dehning, J. et al. Inferring change points in the spread of COVID-19 reveals the effectiveness of interventions. Science https://doi.org/10.1126/science.abb9789 (2020).

13. Chang, S. L., Piraveenan, M., Pattison, P. \& Prokopenko, M. Game theoretic modelling of infectious disease dynamics and intervention methods: a review. J. Biol. Dyn. 14, 57-89 (2020).

14. Gros, C., Valenti, R., Schneider, L., Valenti, K. \& Gros, D. Containment efficiency and control strategies for the corona pandemic costs. arXiv:2004.00493 (2020).

15. Walker, P. G. T. et al. Imperial College COVID-19 Response Team. The global impact of COVID-19 and strategies for mitigation and suppression. Science. https://doi.org/10.1126/science.abc0035 (2020).

16. Dignum, F. et al. Analysing the combined health, social and economic impacts of the corovanvirus pandemic using agent-based social simulation. Minds Mach. 30, 177-194 (2020).

17. Fair, K. M., Zachreson, C. \& Prokopenko, M. Creating a surrogate commuter network from Australian Bureau of Statistics census data. Sci. Data 6, 150 (2019).

18. Kucharski, A. J. et al. Early dynamics of transmission and control of COVID-19: a mathematical modelling study. Lancet Infect. Dis. https://doi.org/10.1016/S1473-3099(20)30144-4 (2020).

19. Linton, N. M. et al. Incubation period and other epidemiological characteristics of 2019 novel coronavirus infections with right truncation: a statistical analysis of publicly available case data. J. Clin. Med. 9, 538 (2020).

20. Lokuge, K. et al. Exit strategies: optimising feasible surveillance for detection, elimination and ongoing prevention of COVID-19 community transmission. medRxiv https://doi.org/10.1101/2020.04.19.20071217 (2020).

21. Buchan, A.G., Yang, L. \& Atkinson, K.D. Predicting airborne coronavirus inactivation by far-UVC in populated rooms using a high-fidelity coupled radiation-CFD model. Sci Rep 10, 19659 (2020). https://doi.org/10.1038/s41598-020-76597-y

22. Liu, Y. et al. Aerodynamic analysis of SARS-CoV-2 in two Wuhan hospitals. Nature 1-4 (2020).

23. Zhang, R., Li, Y., Zhang, A. L., Wang, Y. \& Molina, M. J. Identifying airborne transmission as the dominant route for the spread of COVID-19. Proc. Natl. Acad. Sci. USA (2020).

24. Kowalski, W. Ultraviolet Germicidal Irradiation Handbook: UVGI for air and Surface Disinfection (Springer Science \& Business Media, New York, 2010).

25. Weiss, M. M., Weiss, P. D., Weiss, D. E. \& Weiss, J. B. Disrupting the transmission of influenza A: face masks and ultraviolet light as control measures. Am. J. Public Health 97, S32-S37 (2007).

26. Buonanno, M., Welch, D., Shuryak, I. \& Brenner, D. Far-UVC (222 nm) efficiently and safely inactivates airborne human coronaviruses. Sci. Rep. 10, 10285 (2020).

\section{Figures}




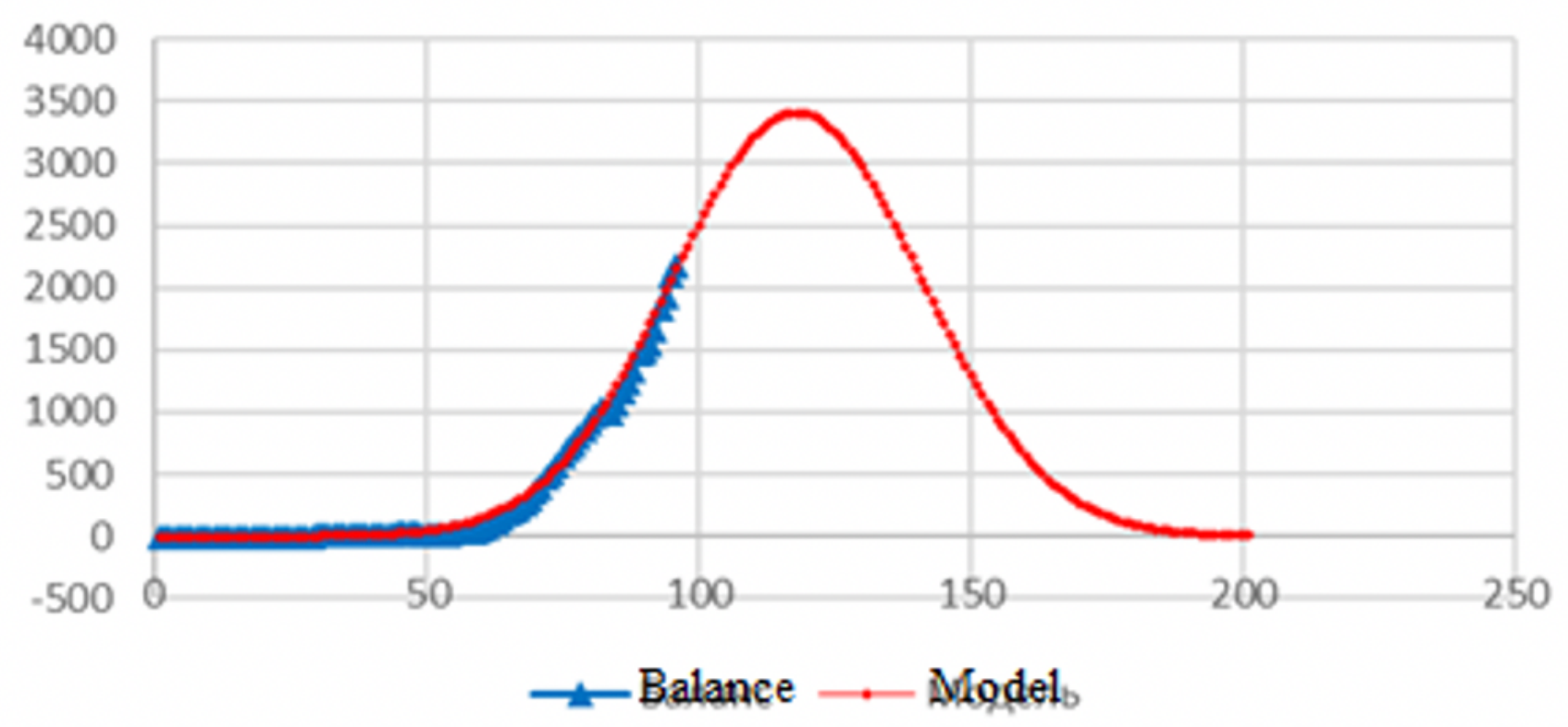

Figure 1

Balance and model (person per day) in Tuva

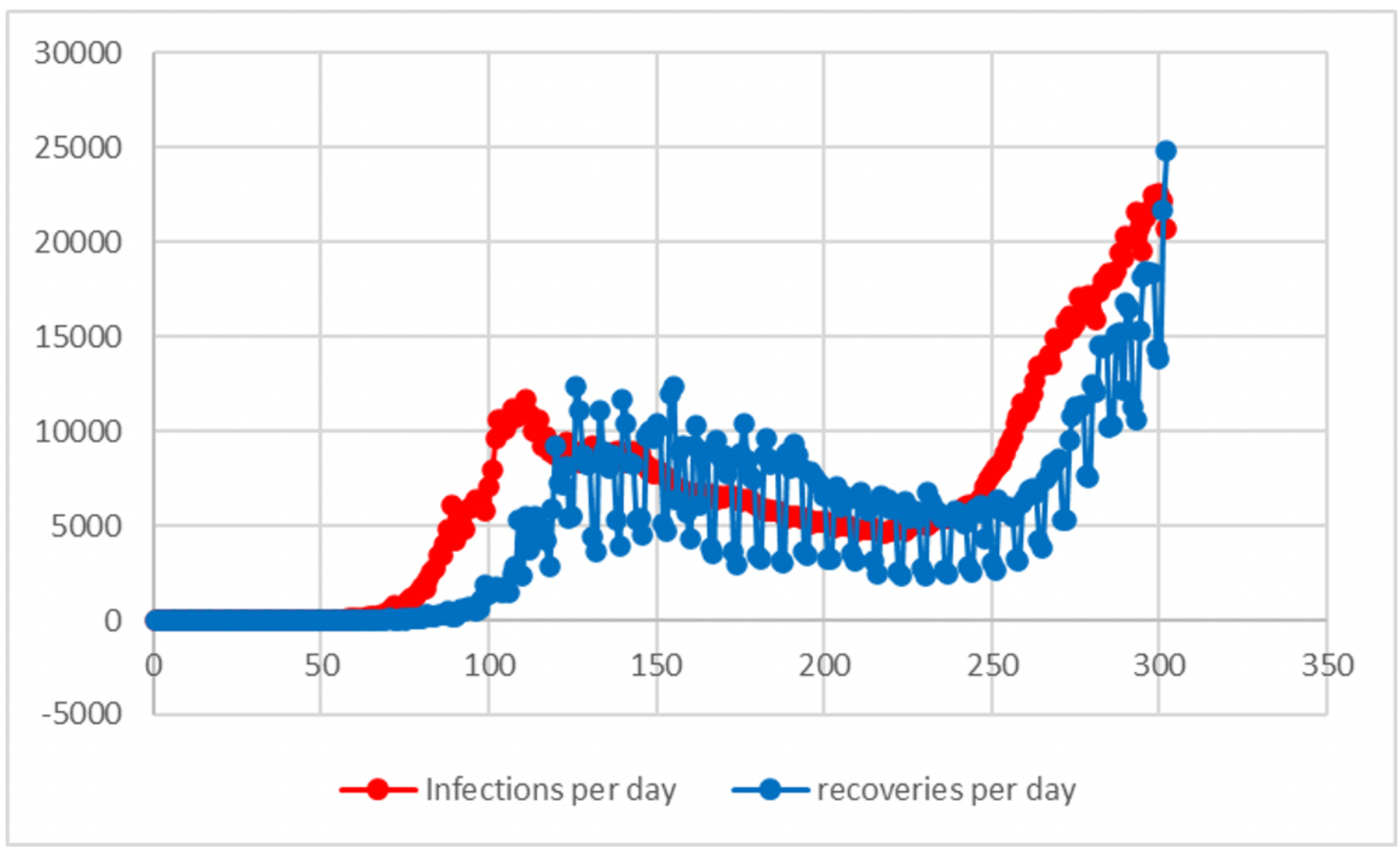

Figure 2 
The spread of COVID-19 in Russia.

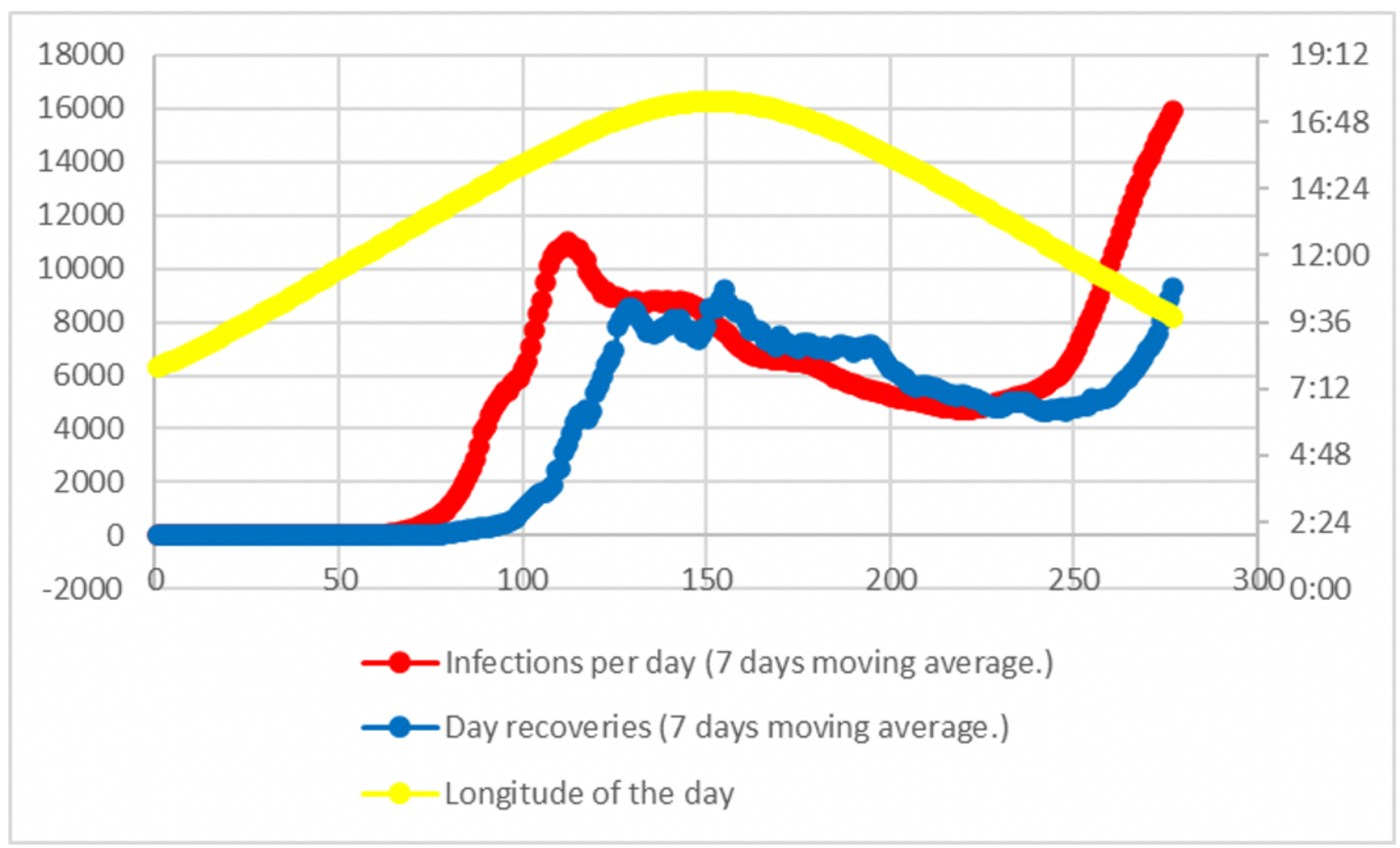

Figure 3

Dependence of the COVID 19 infection process on solar insolation. 


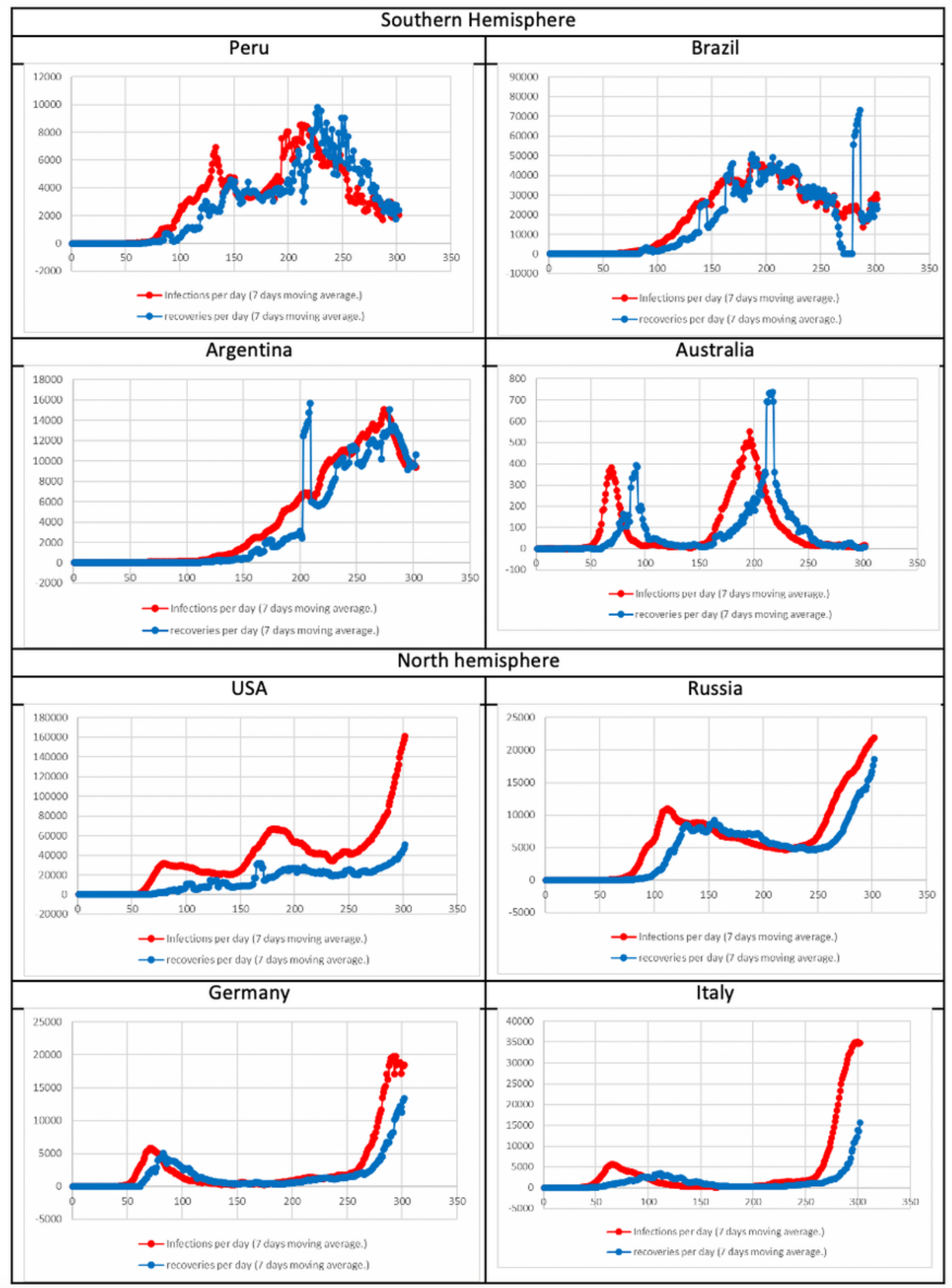

Figure 4

Development of the infection process in the countries of the southern and northern hemispheres. 